Portland State University

PDXScholar

\title{
The Concepts of Mother in Children's Stories in Translation from Print to Visual Media: A Content Analysis
}

Karen Martin Tanski

Portland State University

Follow this and additional works at: https://pdxscholar.library.pdx.edu/open_access_etds

Part of the Speech and Rhetorical Studies Commons

Let us know how access to this document benefits you.

\section{Recommended Citation}

Tanski, Karen Martin, "The Concepts of Mother in Children's Stories in Translation from Print to Visual Media: A Content Analysis" (1994). Dissertations and Theses. Paper 4783.

https://doi.org/10.15760/etd.6667

This Thesis is brought to you for free and open access. It has been accepted for inclusion in Dissertations and Theses by an authorized administrator of PDXScholar. Please contact us if we can make this document more accessible: pdxscholar@pdx.edu. 


\section{THESIS APPROVAL}

The abstract and thesis of Karen Martin Tanski for the Master of Science in Speech Communication were presented September 19, 1994, and accepted by the thesis committee and the department.

COMMITTEE APPROVALS:

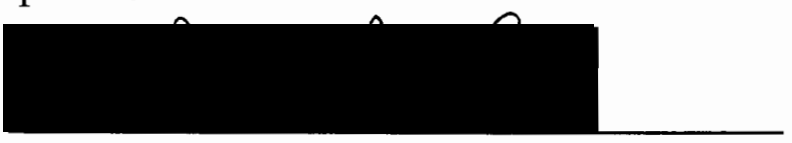

L. David Ritchie, Chair

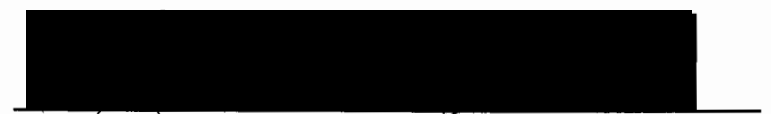

Leslie T. Good

DEPARTMENT APPROVAL:

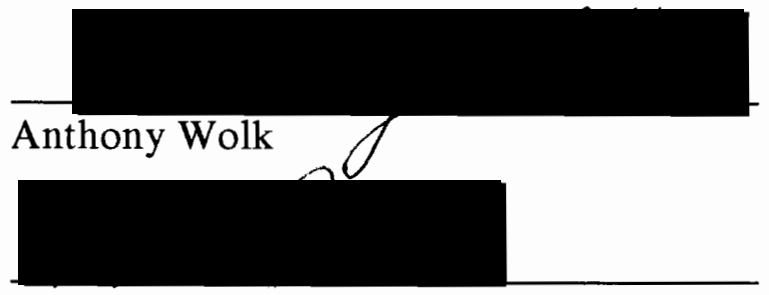

Rhea Paul, Chair

Department of Speech Communication

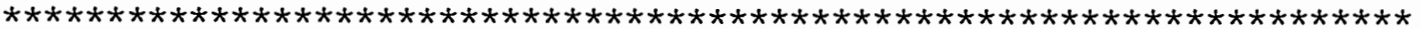

ACCEPTED FOR PORTLAND STATE UNIVERSITY BY THE LIBRARY

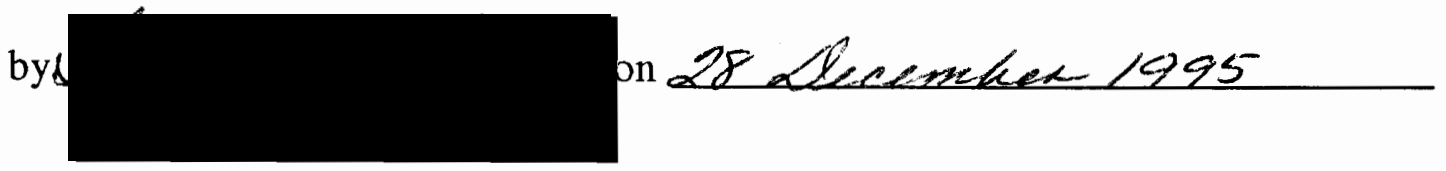




\begin{abstract}
An abstract of the thesis of Karen Martin Tanski for the Master of Science in Speech Communication: presented September 19, 1994.

Title: The concepts of mother in children's stories in translation from print to visual media: A content analysis.
\end{abstract}

The purpose of this research was two-fold. First, this thesis sought to uncover the implicit concepts associated with mothers in children's stories. Second, this thesis attempted to chart changes in portrayals of mother when translated from print to a visual medium. This research maintains that the concepts of mother in children's stories contain cultural ideals that are related to society's evolving perceptions of mother.

Eighteen mother/surrogate mother portrayals were analyzed in 15 novels and 15 videotapes. Each portrayal was coded according to marital status, range of behaviors, 41 individual behaviors within five categories, and the amount of storytime.

The results of this thesis reveal that the two most frequent behaviors associated with the role of mother in both media and print are authority and nurturance.

The research also found that mother portrayals, when translated to film and television, displayed less dominant and less supportive behaviors than in print versions. Of the 41 individual behaviors coded in both novels and videotapes mothers in films and television were found to display less ability and more affection than their print versions. 
In conclusion, this study found that mother portrayals, when translated to film and television, may be altered to increase their mass audience appeal. 
THE CONCEPTS OF MOTHER IN CHILDREN'S STORIES

IN TRANSLATION FROM PRINT TO VISUAL

MEDIA: A CONTENT ANALYSIS

by

KAREN MARTIN TANSKI

A thesis submitted in partial fulfillment of the

requirements for the degree of

MASTER OF SCIENCE

in

SPEECH COMMUNICATION

Portland State University

1994 


\section{ACKNOWLEDGEMENTS}

Although I ultimately accept complete responsibility for this thesis it was never a solo endeavor. Obviously how mothers are portrayed interested me because I'm a mother, and so I thank my husband David, and my daughters, Katherine and Victoria for bestowing upon me the role of mother.

I am also extremely grateful for the help and support of Dr. Ritchie who displayed extraordinary insight, judgement and patience during a long and tortuous process. Your confidence in me made it impossible for me to quit, even when I thought I could. I have relied upon your expertise and good nature throughout this entire process, thank you.

Thank you too, Dr. Good for the oft needed reassurances and ever present smile. I feel very fortunate to have had the benefit of your input during this project.

Dr. Wolk the proper order of the universe was restored when at the last moment I asked you to be a member of my committee and you accepted. This thesis is a result of the proposal I wrote in your class and so it feels right that you should see the final outcome.

Dr. Jacobsen, nearly three years ago I listened fascinated to a discussion of women on television in your class and it was at that moment that I knew what I wanted to be when I grew up, thank you.

Many, many thanks also go to Paula Blunck, Lynn Stanek, Pat Hamilton, Deborah Elam, and Polly Stukey, my friends and colleagues who enccuraged and supported me more than I deserved. 
ACKNOWLEDGEMENTS $\ldots \ldots \ldots \ldots \ldots \ldots \ldots \ldots \ldots$ ii

TABLE OF CONTENTS $\ldots \ldots \ldots \ldots \ldots \ldots \ldots \ldots \ldots \ldots$

LIST OF TABLES $\ldots \ldots \ldots \ldots \ldots \ldots \ldots \ldots \ldots \ldots \ldots \ldots \ldots \ldots$

\section{CHAPTER}

I INTRODUCTION $\ldots \ldots \ldots \ldots \ldots \ldots \ldots \ldots \ldots \ldots$

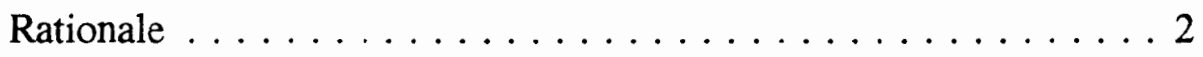

II THEORETICAL FOUNDATION $\ldots \ldots \ldots \ldots \ldots \ldots \ldots$

Culture and stories $\ldots \ldots \ldots \ldots \ldots \ldots \ldots$

Social Learning theory $\ldots \ldots \ldots \ldots \ldots \ldots$

Social Conception of Mother $\ldots \ldots \ldots \ldots \ldots \ldots \ldots$

Cultivation Theory $\ldots \ldots \ldots \ldots \ldots \ldots \ldots \ldots \ldots \ldots \ldots \ldots \ldots \ldots$

III REVIEW OF LITERATURE $\ldots \ldots \ldots \ldots \ldots \ldots \ldots \ldots$

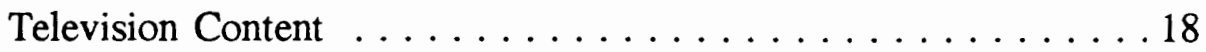

Children's Literature Content $\ldots \ldots \ldots \ldots \ldots \ldots \ldots$

Literature's Influence on Television Content . . . . . . . 23

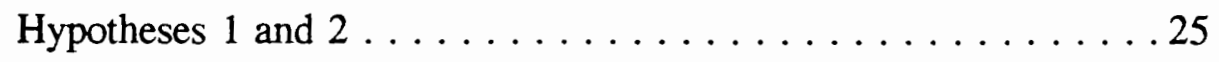

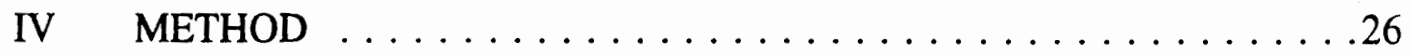

Purpose of the Study $\ldots \ldots \ldots \ldots \ldots \ldots \ldots$

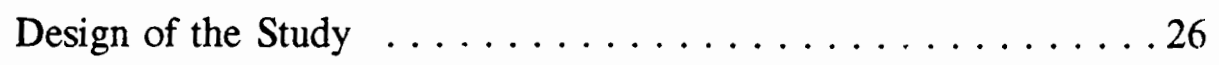

Sample selection $\ldots \ldots \ldots \ldots \ldots \ldots \ldots \ldots \ldots \ldots \ldots$ 
Coding Method $\ldots \ldots \ldots \ldots \ldots \ldots \ldots \ldots \ldots \ldots \ldots \ldots \ldots \ldots \ldots \ldots$

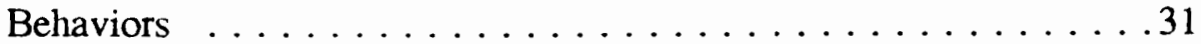

Hypotheses 3 through $9 \ldots \ldots \ldots \ldots \ldots \ldots \ldots \ldots$

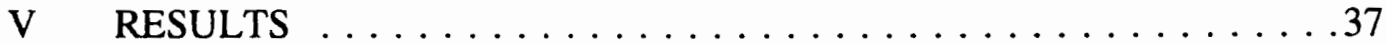

Test-retest reliability $\ldots \ldots \ldots \ldots \ldots \ldots \ldots \ldots \ldots \ldots \ldots$

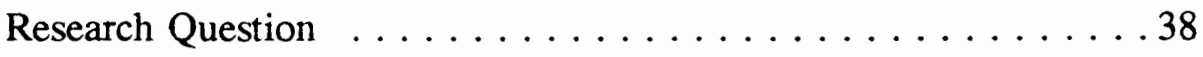

Hypothesis Tests . . . . . . . . . . . . . . . 42

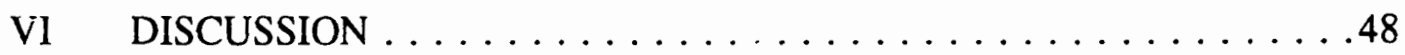

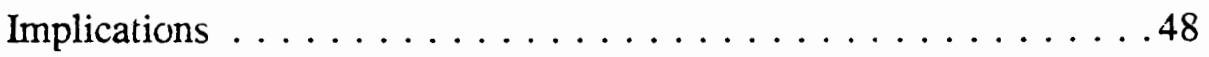

Limitations . . . . . . . . . . . . . . . .51

REFERENCES $\ldots \ldots \ldots \ldots \ldots \ldots \ldots \ldots \ldots \ldots \ldots \ldots \ldots \ldots \ldots \ldots \ldots \ldots$

APPENDICES

A BEHAVIOR DEFINITIONS $\ldots \ldots \ldots \ldots \ldots \ldots \ldots \ldots$

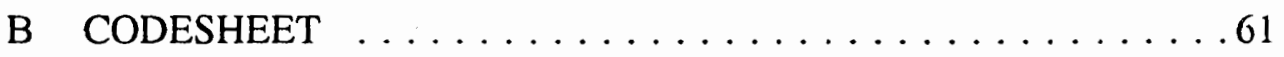




\section{LIST OF TABLES}

TABLE

PAGE

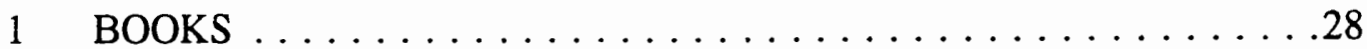

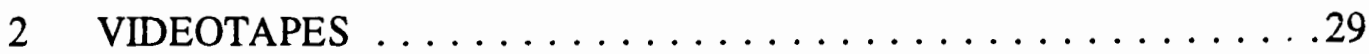

3 BEHAVIORS--BOOKS ... . . . . . . . . . . . . . . . 39

4 BEHAVIORS--FILM AND TELEVISION $\ldots \ldots \ldots \ldots \ldots \ldots$

5 TOP 7 BEHAVIORS--BOOKS AND FILMS $\ldots \ldots \ldots \ldots \ldots \ldots$

6 BEHAVIOR CATEGORY COMPARISON $\ldots \ldots \ldots \ldots \ldots \ldots 4$

7 INDIVIDUAL BEHAVIOR COMPARISON $\ldots \ldots \ldots \ldots \ldots 47$ 


\section{CHAPTER I}

\section{INTRODUCTION}

\section{OVERVIEW}

This study looks at the portrayal of mothers in children's media. Specifically, it traces the behaviors of mothers and surrogate mothers in children's novels when translated to feature films and television dramas. Consequently this study has two goals. The first goal is to look at how mothers are portrayed in children's stories. Particularly, this study asks: What specific behaviors define the role of mother? and What qualities are most closely associated with the role of mother? A second goal of this study is to document changes in mother portrayals, if any, when stories are translated from print to visual media.

This thesis is divided into six chapters. The first chapter details the rationale for this research. The second chapter lays the theoretical foundation for this study. Chapter III reviews relevant literature in the area of mass media content. The Method chapter discusses the design of the study, including research method, data gathering instruments, and data collection and analysis procedures. The results of these analyses are reported in the fifth chapter, specifically the test-retest reliability, research questions and hypothesis tests. 
Chapter VI suggests an interpretive framework within which to view the findings and discuss the implications of this study for future research. The final chapter states the limitations of this work and suggests further research.

\section{Rationale}

\section{Role of Mother}

Family life in U.S. culture is in a period of intense examination by the media and society. Currently there are several magazines devoted to parenting, single parenting and couple relationships. Under specific and intense scrutiny in society and within the family is the role of the mother. Because many women are exploring what it means to be a mother and what is expected of mothers in this society it is incumbent upon us to look at portrayals of mother in the media, and in particular children's media,

Particularly notable is the lack of mothers or surrogates in children's novels. The main characters of children's stories are often orphaned or separated from their families. In addition to addressing the questions articulated above I also ask: Why are there so few mothers in children's literature?

\section{Culture and Stories}

It is an underlying assumption of this study that cultural assumptions and the role expectations they generate for "mother" are identifiable in the stories we tell our children. Hence, the mother's lack of representation in children's literature is both 
perplexing and fascinating. If we assume that part of the purpose of storytelling is to impart social knowledge and that family roles must be included as part of this subject, then we also must assume there is an identifiable reason for the absence of mothers from children's stories.

Social Learning Theory

The conveyance of social knowledge is primary to the study of media content. Portrayals of sex-roles and social roles on television and in other media are often the subjects of media research. In turn, the effects of these portrayals on children are another frequent topic of media research. These studies fall under the broad theoretical perspective of Social Learning Theory that maintains that Social Learning takes place through modeling behaviors represented in mass media. It is precisely because children learn from the mass media that content is an area of research.

Social Conception of Mother

Aside from portraying role models for children, "television and the entertainment mass media in general heavily influence women's identities in our culture" (Press, 1990 p.3). The connection between the media and women's own understanding of the role of mother also must be acknowledged. If children learn idealized versions of mothers from the media, so do women learn idealized standards by which to judge themselves. 
Due to this connection, and due to the primary role of mother in the family unit, an in-depth examination of mother portrayals in children's media is warranted. At the heart of controversies over family values, child care, working mothers, and single mothers are deeply held cultural assumptions about the role of mother. In addition, as stated above, how society culturally constructs the role of mother can have important and far-reaching implications in the lives of individual women.

\section{Cultivation theory}

It is a basic premise of cultivation theory that television is inherently more conservative and traditional in its images and values than other forms of mass media. Gerbner, et al. (1986) assert that television is a "superimposition of a relatively homogeneous process upon a relatively diversified print and film context. (p.19) Further, they state that it is through the demands of television production that "Television differs from other media" (p.19). Therefore, a basic rationale for the comparison of print and visual versions of the same stories is to illuminate the effect of television production upon the specific portrayals of mothers.

\section{Content Analysis}

Content analyses that focus upon the depiction of women in the mass media frequently categorize the role of mother as a "traditional female role" (Signorielli, 1982; Vande Berg \& Streckfuss, 1992; Davis, 1990) and it is usually dismissed as stereotypical. Additionally, the role of mother is often grouped with housewife or 
homernaker, or as Hawkins \& Aber (1993) described one general category "housewives, mothers, ornaments, waitresses, health care workers, secretaries" (p.238). If this categorization is based on the premise that women on television are "usually presented in a home, family, or marital context" (Signorielli 1982, p.586) then classifying the role as a "traditional" female depiction is not unreasonable. However, some researchers have suggested that the role of mother itself is necessarily limiting. "Women on prime-time television are portrayed in a much narrower range of rolesprimarily as wives and parents" (Vande Berg \& Streckfuss, 1992) or "women were proportionately more likely to be portrayed as homemakers and proportionately less likely to be portrayed as workers" (Craig, 1992 p.204). Both the media and the researchers unnecessarily devalue parenting and homemaking as productive work and assume that depictions of women as homemakers and mothers are, without exception, stereotypical.

Yet, other studies have noted changing depictions of families in the media. For instance Cantor (1990) found,

Despite ...continuities today's family programs differ from those of the 1950's and 1960's ( 1989a,1989b) Women are more independent. Fathers are more caring and more domesticated. In most series men and women are relatively equal--loving sensitive, professional. But although both husband and wife may be employed there is little competition between them. (p.282)

Moore, (1992) in his analysis of the family on prime-time television, found that "nearly one-half of the total number of females presented as employed outside of the home were members of a conventional family." (p.50) 
In light of these subtle differences in perspectives it is useful to focus on how mothers are portrayed, to focus on the behaviors and traits they exhibit in the media. Further, it might also be useful to conceive of the roles of "mother" and "father" as roles which may or may not be portrayed in a variety of contexts; and which may or may not be portrayed in a stereotypical manner.

Method

Content analysis research can concern itself with manifest content and/or latent content. Manifest content is "--the visibie, surface content-- of a communication" while latent content is "the underlying meaning" of a text (Babbie, 1992, p. 318). This study will concern itself with the manifest content in children's novels and children's film and television. Latent content will be accessed through the interpretation of the manifest content. The underlying meanings I hope to illuminate are the implicit concepts associated with the role of mother.

Through the interpretation of the observable data it should be possible to illuminate the implicit concepts associated with the role of mother. Implicit theories are "organized sets of beliefs [that] consist of 'prototypes' or representations of ideal members of that domain" (Perse, et. al. 1990) By coding the behaviors attributed to the mother characters in 15 children' novels I will extract a representation of the behaviors and traits most closely associated with the role of mother. 
Finally, this inquiry acknowledges that implicit concepts of mother are not fixed, but tied to economic, political, cultural and historical contexts. While this research seeks to uncover implicit cultural expectations of mothers through manifest content, I do not ignore or trivialize the importance of temporal context.

In summation, the purpose of this study is to increase our understanding of the role of mother. Children's stories provide one method of uncovering the implicit cultural concepts associated with the role of mother. It is important to understand the specific concepts in children's stories because children model and internalize the role representations in stories. Individual women also internalize the cultural prescriptions associated with social roles presented in children's media. The advent of television has resulted in the distillation of the traditional perception of social roles into an homogeneous set of "coherent images" (Gerbner, Ibid. p. 19). Therefore, one way to access both the implicit concepts associated with mothers and the effects of television production on material from another medium is through the comparison of mother behaviors in print and visual media. 


\section{CHAPTER II}

\section{THEORETICAL FOUNDATION}

In this chapter I survey in depth the four separate theories of research touched upon in our introduction. The first section draws upon the historical context of the meaning of story within cultures. The second area relates the findings of Social Learning theory to the parameters of this study. Section three explores current research about the social conception of mother. Finally, cultivation theory and its relevance to this study is reviewed.

\section{CULTURE AND STORIES}

When we think of the importance of media in constructing implicit concepts of mother it is necessary to understand the role of storytelling in society.

The relationship between culture and stories has long been acknowledged; Plato identified and recognized the role of "Tales told by nurses and mothers" in maintaining social order. More recently Pope, et al. (1990) state "Culture is a set of stories told over and over again" (p. 441), and Gerbner et al. (1986) maintain "The illumination of the invisible relationships of life and society has always been the principal function of storytelling" (p. 18). 
The role of stories in "legitimating" social reality is defined by Berger \& Luckmann (1966) as "explanatory schemes relating sets of objective meanings. These schemes are highly pragmatic and directly related to concrete actions. Proverbs, moral maxims, and wise sayings are common on this level. Here too, belong legends and folk tales, frequently transmitted in poetic forms...Thus the child learns such adages" (p.47).

It can be assumed then that stories and storytelling serve an important cultural function. They impart and reinforce cultural information about social relationships, roles and patterns. Because children learn social information from fictional stories it makes sense to examine the content of those stories. However, uncovering cultural values and patterns from manifest content can be difficult because cultural information is often inferred. Yet implicit information is a primary source of learning for children. Social Learning Theory provides a framework by which to understand the relationship between symbolic modeling and the implicit concepts that influence the attitudes, behaviors and perceptions of children.

\section{Social Learning Theory}

Humans learn from the symbolic activities of society. According to Social Learning Theory "People are aided in acquiring social, vocational and recreational skills by following written descriptions of how to behave" (Bandura, 1977, p.39) and "both children and adults acquire attitudes, emotional responses, and complex patterns of behavior through exposure to pictorially presented models" (Bandura, 1971 p.41). 
Further, in the case of social roles, behavior not immediately modeled can be stored symbolically and "activated into overt performance [when] age or social status deems the activity appropriate" (Bandura, 1977 p.39). Storage of information for future use is an important consideration for analyzing the portrayal of adult roles in children's media. This argument is further strengthened by the prominence of the media in the lives of children. As Bandura states "Another influential source of social learning is the aburdant and varied symbolic modeling provided by television, films and other visual media. It has been shown that children and adults acquire attitudes, emotional responses, and new styles of conduct through film and televised modeling." (p. 39) Children also extract, through the process of abstract modeling, "the conımon attributes exemplified in diverse modeled responses and formulate rules for generating behavior with similar structural characteristics". (Bandura, 1977 p.41). Abstract modeling might then be directly related to the creation of implicit theory. As a child leanns the rules for behavior associated with particular roles, these rules become characteristics the child associates with the roles. As these implicit characteristics are reinforced they become the "common attributes" which define the social role for the child, hence the implicit theory by which roles are judged.

While media content is not the only source of learning for children "the mass media play an infiuential role in shaping behavior and social attitudes." (p.49) Bandura further suggests that, "with increasing use of symbolic modeling...parents, teachers, and other traditional role models may occupy less prominent roles in social learning." (p.49) Regardless of the impact parents and other role models have on their 
children's upbringing "[people's] perceptions of social reality are heavily influenced by... what they see, hear and read in the mass media." (p.49)

\section{SOCIAL CONCEPTION OF MOTHER}

Media's influence upon the social conception of mother has also been addressed by some researchers. In these inquiries the role of mother is considered in light of its value to the structure of society. Some studies (Tobin, 1990; Spigel,1989; Honey, 1984) have sought to describe the relationship between conceptions of motherhood to the particular historical interests of the dominant institutions in society. Tobin in her analysis of "The Lady's Magazine", a 19th century British joumal, found that changing economic times, namely industrialization and the movement of production from the home to the public sphere, created a new paradigm for domesticity. The new conception of mother was as provider of respite for the family. Her role was to create the home as refuge from public space. The separation of public and private space was a theme carried on throughout the magazine.

Honey's book Creating Rosie the Riveter noted the effort in the media to reconceptualize women as public and competent persons rather than private and dependent females, in an effort to fill wartime with female workers.

Spigel noted the discursive formation of television in the home as offered through women's magazines in the early 50's. Rather than making television a distraction from the duties of the mother the magazines began to show television as something that 
women could enjoy while sewing or mending. Further, television was pictured as an entertainment that would promote family togetherness.

Each of these studies demonstrates that the conception of what "mother" is changes with time. And as Spigel demonstrated one of the most important historical influences on the conception of mother is the mass media.

For Pope, et. al (1990) it is a patriarchal construction of mothering perpetuated in mass media that requires women to adhere to the male authority on mothering. This results in "a world where cultural expectations of mothering speak with a stronger voice than does the actual experience of mothering (p. 445). This patriarchal construction, as put forth by Tobin, Pope, and Honey, is one in which the only "proper" realm of activity for mothers is the domestic realm. This perspective, while outdated by current standards, can still have strong influence upon our conceptions of mother.

For instance Bridges \& Orza (1992) found that mothers who were employed receive lower approval ratings than mothers with infant children who were not employed. And further, those mothers identified as working for personal fulfillment, rather than economic necessity, received even lower approval ratings.

The personal implications can also be costly, as in Fellman's account of the scarred relationship of Laura Ingalls Wilder, an author whose work Little House on the Prairie is analyzed in this study, and her daughter Rose Wilder Lane. The disappointment each woman felt in each other and herself resulted from her inability to live up to the expectations of motherhood. In each of these studies the tension 
between conceptions of a domestic mother and the public economic world are the primary problem.

According to Chodorow (1978) "Women's mothering is central to the sexual division of labor. Women's maternal role has profound effects on women's lives, on ideology about women, on the reproduction of masculinity and sexual inequality, and on the reproduction of particular forms of labor power." (p. 11). The expectation is that a choice between motherhood and career must be made.

Chodorow also reports on the prevalence of mother as sacrificer in psychoanalytic theory, "the accounts of these theorists suggest that good maternal behavior requires both a constant delicate assessment of infantile needs and wants and an extreme selflessness" (p.84). The title of "good mother" requires the suppression of the mother's needs and desires and total attention to the needs and wants of her child, "it is understood that only the selflessly loving mother is good" (Pope et al. 1990, p. 441)

The perspective of a selflessly loving mother is a social conception not limited to psychoanalytic theory. Self-sacrifice was also a persistent theme in the media conceptions recounted by Tobin, (1990) and Honey (1984). As the instituticnal needs changed the concept of selflessness was utilized by the mass media to construct a different view of social reality. 
Cultivation Theory

The influence of television on social reality is the guiding principle behind cultivation theory. Cultivation theory puts forth the idea of a "mainstream social reality" generated from television content.

Through systematic and ongoing content analyses of prime time television dramas, and the systematic administration of surveys to the general population, cultivation research has found heavy television viewing leads to a "television" view of social reality. In fact, television-based perceptions of reality cling to the viewer despite real world evidence to the contrary. For example, Cultivation research (Gerbner \& Gross, 1976) discovered a phenomenon which they termed the "mean world syndrome". This term referred to an effect in which heavy viewers perceived the world to be more violent, dangerous, and dishonest than real world statistics reported.

Cultivation theory also asserts that television is where most people now get their conception of reality. Gerbner, Gross, Morgan, and Signorielli (1986) present a coherent view of television as a "centralized system of storytelling" (p.18). They argue that television has replaced alternative institutions in the socialization process of society. They liken television to religion and explain "The heart of the analogy of television and religion, and the similarity of their social functions, lies in the continued repetition of patterns (myths, ideologies, facts, relationships, etc) which serve to define the world and legitimize the social order" (p.18). The theory of cultivation asserts that television differs from other media "in its centralized mass production and 
ritualistic use of a coherent set of images and messages produced for total populations." (p.19).

Therefore, the underlying assumption for most of Cultivation Theory's assertions is that television content is inherently more traditional in its values than other forms of mass media. Gerbner, et. al. (1986) explain "Television's goal of greatest audience appeal at least cost demands that most of its messages follow conventional social morality". (p.21) They further point to the perception "we are all imbued with the perspectives of print culture and its ideals of freedom, diversity, and an active electorate producing as well as selecting information and entertainment from the point of view of a healthy variety of competing and conflicting interests. (p.20). In contrast, they say "television challenges theories of self-government predicated on print-based assumptions of ideologically diverse, distinct and selective publics conscious of their own divergent interests". (p.21).

A basic assertion of Cultivation theory is that because the content of television is mainstream, it leads to the dissemination of mainstream social models. If Cultivation theory is correct it would follow that we would see the traditional roles of our culture most highly distilled on television.

If I extend this premise for the purposes of our study then I would expect to see a reduction in the diversity of content from novel to television.

To summarize, this study is based upon four premises. First, I maintain that there is a direct relationship between stories and perpetuation of cultural patterns, relationships and values. Second, primary to this relationship is the ability of humans 
to adopt social roles through symbolic modeling processes. Third, the patterns of behaviors and ideal traits presented in stories become the concepts which members of society use to define themselves and others. Finally, we see that the dominant storyteller and source of symbolic modeling in this culture is the mass media. 


\section{CHAPTER III}

\section{REVIEW OF LITERATURE}

This chapter reviews content analyses from both print and visual media. First, I survey the portrayals of sex, family, and social roles on television and, in some cases, the effects of those portrayals on the perceptions of children. The second type looks at portrayals of sex, family and social roles in children's literature.

As stated previously, content analysis is grounded in theory that assumes children learn sex roles and sexual identity from media representations. However, this assumption does not imply that sexual identity or social roles are not learned from social interaction, but each of these studies echoes the assertions of Social Leaming Theory and Cultivation Theory that the authority of the media, and in particular television, acts as a primary source of social information for children. As columnist Paul Kurnit expressed it, "Television is the only universal experience American kids have in common". (1992 p.19) Based on this premise, research has explored the sexrole stereotypes portrayed in the mass media and their subsequent effects on the perceptions of children. 


\section{TELEVISION CONTENT}

It is not surprising that the role of women on television would become a major area of focus. Traditionally, content analyses have focused upon the roles assigned to women and men and the distribution ratios of male and female characters. The studies found an over-representation of women as housewives, mothers (Lovdal, 1989; Signorielli, 1982 \& Beuf 1974) and sex-objects (Seidman, 1992; Davis, 1990). Seidman, succinctly described the state of women on television as "females are often shown as wives and mothers or as objects of sexual desire." (p.215).

It is understandable then that many of these studies lament the characterization of females as exclusively housewives and mothers. Indeed, it is very limiting, for as Signorielli (1982) found, marriage or motherhood on television results in a woman's immediate unemployment.

These depictions on television have been shown to have some influence on perception of career roles, and even social class.

Studies have found that among adolescent television viewers (Beuf, 1974) "76\% of heavy viewers selected stereotyped careers for themselves." Beuf also found "children not only see the world as divided into male and female tasks; they also give the male tasks higher ratings". (pg 144).

Reeves and Miller (1978) used Multi-dimensional scaling to assess the amount of identification children felt with major television characters. The procedure they used most accurately predicted the amount the children felt they wanted to 
"Be like" the television character, but found that the children were not inclined to "do like" the character. The study was limited, however, in female/male distribution in that only 3 of the 14 major television characters were female, due to the lack of major female characters on television.

Related to their finding of "be like" but not "do like" Signorielli \& Lears (1992) found that television influenced perceptions of whether a household chore was designated as "boy" or "girl" but didn't influence what chores the children actually did.

While each study may have focused on a particular type of prograrnming or a specific demographic variable, each study noted the pervasiveness of the television medium in the lives of children.

Not only does television influence sex-role perceptions, it influences how children play. An Ethnographic study conducted by James and Mc Cain (1972) found that pre-school children often used television content in their play. The authors found that even television shows that children had never seen became the basis of many games.

Other studies suggest that children gain interpersonal information from television. Buerkel-Rothfuss et al. (1982) found that "Television is a valued source of learning about family roles and may be used extensively by some children" (p.192). Weiss and Wilson (1993) postulate that children learn emotional strategies from television. This assertion is related to findings that children perceive the situations of television children in family shows to be highly realistic. It is this perception of real life-like 
situations that suggests that portrayals play a part in the way children act and feel about the world.

Adding strength to Cultivation theory's assertion that TV mainstreams traditional values, Perse, et al. (1990) found that college students rated traditional couples on television as happiest when those students' own implicit theories of marriage were also traditional. Both findings in turn suggest an interaction between perception, implicit theory, and media content.

\section{Creating Television Content}

The overwhelming evidence of stereotyped roles for women in every aspect of television content supports the conclusions of Cultivation Theory, that due to "television's centralized mass production" it must follow "conventional social reality" These premises led Vest (1992) to hypothesize that because of television's power relationships "scripts containing initially more diverse ideas and images are altered to the perceived organizational needs of the distributors" (p.25).

He hypothesized that by looking at the initial scripts and comparing them to the final shooting scripts for television pilots he would find an observable and systematic alteration in women's roles. Unexpectedly, the difference in gender representation was to be found in the initially submitted scripts of "proven" producers, not between shooting and final pilot scripts. The scripts of already successful television producers began with fewer and more stereotyped roles for women. He found no measurable differences in women's representations from initial script to shooting script. 
Vest's finding that the most successful producers write less diverse roles supports the idea of story alteration for teievision. Perhaps Vest simply didn't go fat enough back in the process of story production to find the empirical evidence to support his hypothesis. What if I compared the text of original novels to television productions and feature films, would I find systematic alteration?

\section{CHLDREN'S LITERATURE CONTENT}

The content analysis has also been used as a tool for the evaluation of sex roles in children's literature ( Nilsen, 1971; Hillman, 1973; Collins, et.al.1984; Wiiliams, et. al.1987; Korienhaus \& Demarest, 1993). These studies were "based on the premise that literature plays a meaningful role in shaping a child's cognitive and emotional growth Cuitural standards are presuriably manifest in children's books; the reading process thus allows the school-age child to...identify with models who exhibit sex role behavior." (Hillman, 1973 p.84) Hillman dealt with women in childien's literature between the 1930's and the 1970's, he found a greater variance of behaviors in women, but little variance in occupational roles.

Nilsen, (1971) surveyed Caldecoti Award Winners and runners-up from 1950 through 1970. The Caldecott is an award presented annually by the American Library Association for exceptional picture books. Not surprisingly, she found girls were severely under-represented both in titles and in number of characters. Her assessment of the mother role is especially pertinent to this study: "in one-fourth of the entire 
sample-there were only what I would call token females. Seven of these token females were mothers who sewed on the buttons and packed the lunches" (p. 919).

Caldecott Award winners were surveyed again in 1984 by Collins, et. al. they utilized 17 different factors which focused on the ratios of males and femaies in titles, central roles, and pictures. They concluded there was "a move toward greater sexual equality in children's literature" (p.285)

More recently Caldecott Winters were assessed by Williams, et. al.(1987). Their study focused on the behaviors of the main characters and compared male and femalc frequencies. They found females depicted as more dependent, submissive, nurturing. passive, and subservient than males. In turn they also found that males were depicted as more independent, competitive, persistent, creative, and active, than females. In addition they noted that $26 \%$ of all female adults were pictured indoors.

Focussing both on ratios of males and females in story structure and the behaviors of males and females in a wide selection of children's stories from the 1940's through the 1980 's Kortenhaus \& Demarest (1993) confirmed the findings of Collins et. al (1984). Kortenhaus \& Demarest stated "In fact, the equity ratio of characterizations of males and females has come to be quite closely balanced. The results are not only consistent with the Collins et. al. study but replicated some of the exact ratios" (p.229). However, they found that while there was "increased female representation in titles, central roles, and pictures...the way in which these females are pictured is still sexist and biased...of the 60 books examined that were published between 1970 an 1986, only 1 portrayed a working mother." (p.230-1) In an interesting alternate 
phrasing of one of this study's underlying questions they asked "Why are there so few working mothers represented in children's literature?"(p.231). 


\section{TELEVISION CONTENT AND LITERATURE CONTENT}

In today's mass media environment television content and children's literature content are not completely separate. According to Publisher's weekly "up to 50\% of children's programming comes from books" (p.137). This may be why the children's television watchdog group ACT (Action for Children's Television) produced a guide for encouraging reading through television to "identify examples of past and present 'TV programis, films, and home videos that successfully drarnatize children's stories or inform young viewers about the world of books." (1991, p. 19). Haight (1989) talked witi several authors of children's books about the transition from book to iclevision. The authors felt that due to the demands of television production characters were eliminated and/or became composites of other characters. They observed that "Many good lines have to come out of someone else's mouth." (p.139)

To summarize the findings of media content research, content analyses have foind that women are under-represented on television and in films. Further, research has fourd that women are most often portrayed in traditional sex roles. These roles are highly stereotyped in the media and offer little diversity in behaviors. Consequently, media effects research has found that these portrayals have influenced the way children perceive sex-roles. Finally, children's literature is often the basis for children's video and television productions, and that author's feel story content is noticeably altered. 
Based upon these findings I would expect to find in the transition of mother characters from print to television that:

H1 Mother characters will display a narrower range of behaviors in their film and television versions than in their print versions.

and

H2 Mother characters will display a narrower range of physical features in their film and television versions than in their print versions. 


\section{CHAPTER IV}

\section{METHOD}

Purpose of the study

The purpose of this study is to identify the major behaviors and characteristics associated with the role of mother in children's novels in order to illuminate the implicit theories of mother present in children's stories. Second, this study proposes to assess the changes, if any, in those behaviors and characteristics in the translation of those specific roles to a visual medium. The first section of this chapter details the design of the study, sample selection process, and the coding process used in this study. The next section explains the 41 behaviors coded in the study and justifies their incorporation. The final section states additional hypotheses suggested through development of the final coding process.

Design of the Study

The study was a content analysis of 15 novels and 15 videotaped film and television presentations. The units of analysis were 18 mother/surrogate portrayals in the novels and 18 mother/surrogate portrayals in the videotapes. The units of observation were 41 separate behaviors. The 41 behaviors were combined into 5 different behavior categories and all were analyzed by paired t-test. 
Sample Selection

The selected sample consists of 18 mother or surrogate mother characters in 15 children's novels. The sample was chosen on the basis of four very specific criteria. First and foremost, this study required a children's or young adult story that had been translated to a visual medium. Second, it was necessary for the story to have a mother/surrogate present in both the print and visual versions of the story. My third requirement was one of convenience, both the printed version and the visual version had to be readily available at the time for the study. Finally, the story had to be available to and selected by children and families on a regular basis. ${ }^{1}$

The characteristics of our selected sample are described below. Of the 18 portrayals 11 were "True mother" and 7 were "Surrogate mother". The visual stories were feature films, television movies or series. Of the 15 separate video sets 11 were feature films and 4 were television productions. Because temporal concerns may affect the findings, copyright dates for each novel were noted as well as release dates for each film. Of the 15 novels 11 were copyrighted pre-television, and 4 were published prior to the invention of the motion picture. All of the feature films had release dates post 1950. I am noting the dates for two reasons, first we can assume that all pre-television novels and pre-motion picture novels had no visual mass media cultural influences. In other words in post-television novels we cannot assume that visual media, or the prospect of translation into a visual media, has had no influence.

\footnotetext{
'This last criterion was partially determined by speaking to a local children's librarian. The particular library contacted also had an extensive children's videotape collection so titles which met the first three criteria were selected with help from Children's librarian Carol Sibray, Tualatin Public Library. (See Tables 1 and 2 for complete list).
} 
As such I feel that any changes that take place in the translation process must be considered in light of these influences, or lack of them.

TABLE 1 Books

1. Little Women, copyright 1875

2. Swiss Farnily Robinson, copyright 1812

3. Little House on the Prairie, copyright 1935

4. The Black Stallion, copyright 1941

5. Peter Pan, copyright 1911

6. Mary Poppins, copyright 1934

7. Mrs. Frisby and the Rats of NIMH, copyright 1971

8. Old Yeller, copyright 1956

9. Charlotte's Web, copyright 1952

10. Sarah Plain and Tall, copyright 1985

11. Anne of Green Gables, copyright 1908

12. National Velvet, copyright 1935

13. The Adventures of Huckleberry Finn, copyright 1885

14. The Jungle Books, copyright 1893-1895 (published in serial format)

15. Winnie the Pooh, copyright 1926. 
TABLE 2

Feature Films (Animated)

1. Peter Pan, 1960

2. The Secret of Nimh, 1985

3. Charlotte's Web, 1971

4. Jungle Book, 1970

Feature Films (Live action)

5. Swiss Family Robinson, 1964

6. Mary Poppins, 1964

7. The Black Stallion, 1979

8. National Velvet, 1950

9. Little Women, 1950

10. Old Yeller, 1965

11. The Adventures of Huckleberry Finn, 1993

Made for TV movies

12. Little House on the Prairie, 1980

13. Sarah Plain and Tall, 1991

14. Anne of Green Gables, 1985

Animated Television series

15. The New Adventures of Winnie the Ponh, 1993 


\section{CODING METHOD}

The novels were coded in several different areas. First, physical descriptions of mother/surrogate were noted, including body size, body type, hair color, eye color, attractiveness and age, this part of the coding scheme was based on Vande Berg and Streckfuss, (1990). Second, marital status of mother/surrogate was noted, whether married, widowed single or divorced. Marital status is a characteristic noted by Signorielli, (1982) and Moore, (1992) and Vest, (1992) as of particular interest in the portrayals of women. As Davis (1990) explains the process it is necessary to look at "marital and parental data [because] women [as wives and mothers] are much more defined in their roles" (p.331).

Each novel was coded as to number of male characters and number of female characters in order to provide the baseline for the analysis of the proportion of female to male characters in the visual mediums. Vest, (1992) and Seidman, (1990), consistent with prior content analyses, reported much higher proportion of male characters on television and Kortenhaus \& Demarest, (1993) noted this same finding in children's literature. A character was defined as anyone in the novel who was given a formal name, not simply a designation of stranger or butcher, and who had some form of verbal communication in the story. 


\section{Behaviors}

The purpose of this part of the study was to answer the questions stated in the Introduction: What do mothers do? and What are mothers like? The best way to obtain this information was to record the behaviors attributed to mothers/surrogates in the novels and to record the behaviors in the visual versions. It was decided that one behavior would be defined as an action that is discrete and observable. Some actions may be seen linked to one another but it was decided that if these linked actions also could occur separately they should be recorded as separate actions. For example, singing to a child while combing her hair was coded as two distinct behaviors. The combing of the child's hair was coded as one childcare task, the singing was coded as an act of nurturance. Using the same line of reasoning, dressing a child, however gently, without an accompanying caress or song was recorded as one childcare task, and not also an act of nurturance. In order to record two separate behaviors, two separate actions were required. In this way linked actions could be recorded separately.

To address the specific question of different mother/surrogate behaviors a coding sheet was designed which listed 41 separate behaviors (see appendix for copy of sheet utilized by coders) selected on the basis of prior content analyses that analyzed the representations of male and female actions both in children's literature and on television.

Seidman's study of female behaviors depicted in music videos (1992) provided 11 of the terms used in this study. These were Adventurous, Affection, Anger, 
Aggression, Dependency, Dominance, Fearful, Nurturance, Sadness, Victimized, and Violence. Five other terms Reassurance, Authority, Advising, Problem Solving and Conflict Resolution were behaviors taken from Vande Berg and Streckfuss (1992) in their study of television's portrayal of women and work. In their study they found that with the exception of reassuring, these behaviors were most often present in male characters and absent in female characters. They also noted that emotionality, nurturing and reinforcing (reassuring), and in need of emotional support were traits most often attributed to women.

The task behaviors of Housework, Caring for Children, and the passive behaviors watching others play, needing help, (rescued) were taken from the Kortenhaus and Demarest (1993) survey of behaviors in children's literature.

In addition to the behaviors garnered from prior content analyses, several behaviors were selected because of their particular association, positive or negative, with "mother roles". These terms included Worried, Self-sacrificing, Makes things go smoothly, Timid, Courteous, Exhaustion, Self-deprecating, Protects, Criticism and Neglect.

Still other terms were added as counterpoints to the terms drawn from other content analyses. Courage was added as an opposite of fearful, Happiness/Playful was added to offset Sadness, Intelligence to offset Ignorance.

Finally, terms were added at the discretion of the primary coder if it was determined that a behavior not on the list was occurring with regularity. The terms Special Powers, Annoyance, Surprise and Curiosity were added in this manner. 
For ease of coding and analysis the 41 behaviors were then divided into 5 major categories, Dominant, Dependent, Supportive, Aggressive, and Independent action or emotion. The terms Aggressive, Dominant and Independent were utilized by Welch Huston-Plein, et. al. (1979) which influenced their inclusion in the 5 major categories.

The selected Dominant behaviors or traits were Ability, Adventurous, Advising, Authority, Courage, Intelligence, Managing, Problem Solving, and Special Powers. A dominant behavior was defined as a behavior which was not dependent upon another's actions and which took a leadership or authoritative role in the story. (For the individual definitions of all 41 behaviors used by the coders please see Appendix A)

The next behavior category was Dependent. These traits and behaviors included Dependency, Exhaustion, Fearful, Foolish, Ignorant, Ill or Injured, Manipulated, Passive, Rescued, Self-Deprecation, Timidity, Victimized, Worried. Dependent behaviors were explained as behaviors which communicated subservience, reliance upon another for support, or actions which were directed or controlled by another.

The third behavior category consisted of Supportive terms and behaviors these were, Affectionate, Childcare Tasks, Courtesy, Housework, Cooking, Makes things go smoothly, Nurtures, Protects, Reassures, Self-sacrifice, and Resolves Conflicts. A supportive behavior was defined as a behavior which provided for another, aided or was performed for the benefit of others.

In the fourth behavior category, Aggressive, the traits and actions coded were Anger, Annoyance, Criticism, Manipulation, Neglect, and Violence. The overall term 
Aggressive was selected because all the above listed actions implied an intent to harm or dominate another person in some way.

The final category was termed Independent Action or Emotion, these were actions which were independent and instrumental but did not fall into the Dominant, Aggressive, or Supportive categories. These included Happiness/Playful, Sadness, Surprise, and Curiosity.

Through the creation of this highly specific behavior coding set, developed to answer our first two hypotheses, five highly specific hypotheses were also suggested:

H3 Mother and surrogate mother characters will display fewer dominant behaviors in film and television versions of children's stories than in the print versions of those same stories.

H4 Mother and surrogate mother characters will display more dependent behaviors in film and television version of children's stories than in the print versions of those same stories.

H5 Mother and surrogate mother characters will display more supportive behaviors in film and television versions of children's stories than in the print versions of those same stories.

H6 Mother and surrogate mother characters will display fewer aggressive behaviors in film and television versions of children's stories than in the print versions of those same stories. 
H7 Mother and surrogate mother characters will display fewer independent actions and emotions in film and television versions of children's stories than in the print versions of those same stories.

Finally in response to the two issues of a lower amount of screen time devoted to female characters and the lower amount of female characters as noted in the Vest ${ }^{2}$ study, this study predicts:

H8 The amount of female characters will decrease in film and television versions of children's stories when compared to the original versions of those same stories.

H9 The percentage of story time devoted to Mother and surrogate mother characters will decrease in film and television versions of children's stories when compared to the original print versions of those same stories.

All the novels were coded by the primary coder, hereafter referred to as "PC". Test-retest reliability was assessed by coding 20 pages of a separate novel and then recoding the novel 4 weeks later. The PC also coded all videotapes, with a separate sample 20 minutes of another story also used to assess test-retest reliability.

\footnotetext{
${ }^{2}$ Vest based his two hypotheses in this area on several content analyses of prime time television, most notably Gerbner, Gross, Morgan \& Signorielli, 1980.
} 


\section{ANALYSIS}

Behaviors and their frequency were coded and tabulated to answer the research questions concerning the characteristics and traits associated with mothers. The statistical significance of observable difference between print and visual mediums was assessed with the paired difference t-test. 


\section{CHAPTER V}

Results

This chapter presents the results of the content analysis of the 15 children's novels. Again, the purpose of this study was two-fold: the first purpose was addressed by the research question "How are mothers portrayed in children's novels"? The second purpose of this study was to map the changes, if any, in portrayals of mother when they are translated from print to a visual medium, addressed by the nine hypotheses. The first section reports the test-retest reliability. The second section, in answer to my research question, looks at the behaviors identified as "motherly" in the sample. The third section addresses each of the nine hypotheses. All hypothesis tests were conducted by using SPSS-X.

\section{TEST-RETEST RELIABILITY}

The test-retest reliability was computed using the following formula:

$\begin{array}{ll}\text { \#CODED BEHAVIORS AGREE } & =\text { RELIABILITY } \\ \text { \#BEHAVIORS POSSIBLE } & \text { SCALE }\end{array}$

Utilizing this formula for both samples, test-retest reliability rates were $95 \%$. 


\section{RESEARCH QUESTION}

For the 18 mother/surrogate mother characters in 15 novels a total of 3,476 instances of 41 different behaviors were coded. (See Tables 3 and 4 for a list of the 41 behaviors and their frequency). By far the most common behavior type for mothers in the novels was Authority with a frequency of 736 , or $21 \%$ of total. It is interesting to note that most cases of Authority behavior consisted of telling children or other family members what to do, for example: "Brush your teeth", "Go to bed" or "Bring in some water". The second most frequent behavior type was Nurtures at 432 and $12 \%$ of total. (See table 5 for a comparison of the top 7 behavior types for print and visual versions) Housework/Cooking was the third most frequent behavior type at 357 acts and $10 \%$ of total behaviors. Dependency was fourth with a total of 241 occurrences and $7 \%$ of total behaviors. The definition of dependency included waiting for someone else to act, deferring to another's opinion or authority or receiving help in some way, getting a large pot off the fire or opening a jar. Dependency coded in this manner ranked well above several other behaviors. The fifth and sixth most frequent mother behaviors were Fearful and Childcare Tasks with $5 \%$ and $4 \%$ of total respectively. 
TABLE 3 MOTHER/SURROGATE BEHAVIORS--BOOKS

\begin{tabular}{||r|r|r||l|r|r||}
\hline \multicolumn{1}{|c|}{ BEHAVIOR } & FREQ & PROP & \multicolumn{1}{|c|}{ BEHA VIOR } & FREQ & PROP \\
\hline AUTHORITY & 736 & .211 & PROBLEM & 41 & .011 \\
\hline NURTURES & 432 & .124 & ADVENTUROUS & 36 & .010 \\
\hline HOUSEWORK & 357 & .102 & SPECIAL POWERS & 36 & .010 \\
\hline DEPENDENCY & 241 & .069 & SURPRISE & 36 & .010 \\
\hline FEARFUL & 160 & .046 & COURAGE & 34 & .009 \\
\hline CHILDCARE & 142 & .040 & IGNORANCE & 30 & .008 \\
\hline CRITICISM & 136 & .039 & ILL OR INIURED & 17 & .004 \\
\hline WORRIED & 93 & .026 & SELF & 17 & .004 \\
\hline INTELLIGENCE & 89 & .025 & VICTIMIZED & 17 & .004 \\
\hline AFFECTION & 81 & .023 & EXHAUSTION & 16 & .004 \\
\hline COURTEOUS & 78 & .022 & TIMID & 13 & .003 \\
\hline ABILITY & 72 & .020 & VIOLENCE & 13 & .003 \\
\hline PROTECTS & 70 & .020 & CURIOSITY & 11 & .003 \\
\hline FOOLISH & 66 & .018 & REASSURES & 11 & .003 \\
\hline ADVISING & 64 & .018 & RESCUED & 09 & .002 \\
\hline HAPPINESS & 62 & .017 & MANAGING & 02 & .000 \\
\hline SELF-SACRIFICE & 61 & .017 & MANIPULATED & 02 & .000 \\
\hline PASSIVE & 53 & .015 & NEGLECTS & 01 & .000 \\
\hline ANNOYANCE & 50 & .014 & RESOLVES & 01 & .000 \\
\hline ANGER & 43 & .012 & SMOOTHLY & 00 & .000 \\
\hline SADNESS & 42 & .012 & & & \\
\hline \hline
\end{tabular}


TABLE 4 Mother/surrogate Behaviors---Film and Television

\begin{tabular}{|c|c|c|c|c|c|}
\hline BEHAVIOR & FREQ & PROP & BEHAVIOR & FREQ & PROP \\
\hline AUTHORITY & 497 & .185 & SURPRISE & 26 & .009 \\
\hline NURTURES & 358 & .133 & SELF-SACRIFICING & 25 & .009 \\
\hline DEPENDENCY & 237 & .088 & $\begin{array}{l}\text { PROBLEM } \\
\text { SOLVING }\end{array}$ & 18 & .006 \\
\hline HOUSEWORK & 194 & .072 & SPECIAL POWERS & 17 & .006 \\
\hline WORRIED & 137 & .051 & TIMID & 16 & .005 \\
\hline AFFECTION & 132 & .049 & ADVISING & 16 & .005 \\
\hline FEARFUL & 129 & .048 & VICTIMIZED & 15 & .005 \\
\hline COURTEOUS & 93 & .034 & IGNORANCE & 13 & .004 \\
\hline HAPPINESS & 91 & .033 & RESCUED & 12 & .004 \\
\hline ANNOYANCE & 85 & .031 & $\begin{array}{l}\text { SELF } \\
\text { DEPRECATING }\end{array}$ & 11 & .004 \\
\hline PASSIVE & 78 & .029 & CURIOSITY & 07 & .002 \\
\hline CRITICISM & 74 & .027 & REASSURES & 07 & .002 \\
\hline CHILDCARE & 71 & .026 & EXHAUSTION & 05 & .001 \\
\hline INTELLIGENCE & 64 & .023 & VIOLENCE & 05 & .001 \\
\hline ANGER & 56 & .020 & ILL OR INJURED & 03 & .000 \\
\hline FOOLISH & 49 & .018 & MANIPULATED & 02 & .000 \\
\hline ABILITY & 36 & .013 & SMOOTHLY & $\infty$ & .000 \\
\hline COURAGE & 34 & .012 & $\begin{array}{l}\text { RESOLVES } \\
\text { CONFLICT }\end{array}$ & $\infty$ & .000 \\
\hline SADNESS & 27 & .010 & MANAGING & 00 & .000 \\
\hline PROTECTS & 27 & .010 & NEGLECT & 00 & .000 \\
\hline ADVENTUROUS & 26 & .009 & & & \\
\hline \multicolumn{4}{|l|}{ TOTAL } & 2,683 & .981 \\
\hline
\end{tabular}


The top six behaviors for the 2,683 total Film and television behaviors ranked somewhat differently. Again Authority 497, 19\%, Nurtures 358, $13 \%$ ranked 1 and 2 but dependency came third $237,9 \%$ rather than fourth and housework $194,7 \%$ took fourth rather than third. In the fifth spot fearful was replaced by worried $137,5 \%$ and sixth was affection $132,5 \%$ rather than childcare.

TABLE 5 Top 7 Behaviors Books and Films

BOOKS
\begin{tabular}{||c|c|c|||l|c|c||}
\hline \multicolumn{1}{|c|}{ BEHAVIOR } & FREQ & PROP & & \multicolumn{1}{c|}{ BEHLM AND TELEVISION } \\
\hline \hline AUTHORITY & 736 & .211 & & FREQ & PROP \\
\hline NURTURES & 432 & .124 & AUTHORITY & 497 & .185 \\
\hline HOUSEWORK & 357 & .102 & NURTURES & 358 & .133 \\
\hline DEPENDENCY & 241 & .069 & DEPENDENCY & 237 & .088 \\
\hline FEARFUL & 160 & .046 & HOUSEWORK & 194 & .072 \\
\hline CHILDCARE & 142 & .040 & WORRIED & 137 & .051 \\
\hline CRITICISM & 136 & .039 & AFFECTION & 132 & .049 \\
\hline \hline TOTAL & 2,204 & .631 & FEARFUL & 129 & .048 \\
\hline
\end{tabular}

Marital Status for the 18 characters was divided into 4 groups, Married, 10; Widowed, 3; Single, 5.

As outlined in the methods chapter, nineteen of the 41 behaviors were identified as stereotypical based on sex role studies (Williams \& Bennett (1974), Seidman, (1992) Williams et al (1984). Those 19 behaviors totalled $58 \%$ of all book behaviors and $61 \%$ of all movie behaviors. 


\section{HYPOTHESIS TESTS}

Dependent $t$-tests were used to analyze the data because I was working from a baseline measurement, in the form of the novel, and then recording changes when that novel was acted upon by a variable, translation to a visual medium. Hence, I could not make the assumption of independent observation required by the chi square analysis. The paired t-test is used "to compare average scores of samples which are paired in some way...or to compare the average scores of a single sample assessed at two different times. (Jaeger, 1990 p. 210) Because the first and second samples were the same essential characters it was decided that the paired t-test was the most applicable test to use. Hence, each of the hypothesis t-tests is based on $n=18$ for book characters and $\mathrm{n}=18$ for film and television characters. (See Table 6 for Hypothesis T-test means and standard deviations.)

H1 stated:

Mother characters will display a narrower range of behaviors in their film and television versions than in their print versions.

This hypothesis was not supported by the results. The results of the dependent $t-$ test were not significant with a Print behaviors mean of 20.47 and Visual behaviors mean of $18.35(t=1.79, d f=17)$. The null hypothesis could not be rejected.

H2 stated:

Mother characters will display a narrower range of physical features in their film and television versions than in their print versions. 
This hypothesis was not tested due to the lack of physical descriptions of mother in the novels: of the 15 novels, only two provided any kind of physical description.

H3 stated:

Mother and surrogate mother characters will display fewer dominant behaviors in film and television versions of children's stories than in the print versions of those same stories.

This hypothesis was supported, with mother/surrogates displaying a mean of 65.11 dominant behaviors in print versions, compared to a mean of 41.23 in the film and television versions $(\mathrm{t}(17 \mathrm{~d} . \mathrm{f})=2.89,. \mathrm{p}<.01)$. The null hypothesis was rejected.

H4 stated:

Mother and surrogate mother characters will display more dependent behaviors in film and television versions of children's stories than in the print versions of those same stories.

This hypothesis was not supported by the data. Mother/surrogates displayed a mean of 45.11 dependent behaviors in print and a mean of 40.41 in the visual versions of the stories (t $(17$ d.f. $)=1.16$ n.s. $)$. The null hypothesis could not be rejected.

H5 stated:

Mother and surrogate mother characters will display more supportive behaviors in film and television versions of children's stories than in the print versions of those same stories.

This hypothesis was not supported by the data, to the contrary supportive behaviors decreased by a significant amount. Mother/surrogates displayed a mean of 
73.00 supportive behaviors in books compared to a mean of 50.23 supportive behaviors in film and television versions ( $(17$ d.f.) $=2.54, \mathrm{p}<.021)$. In this case the null hypothesis could not be rejected.

H6 stated:

Mother and surrogate mother characters will display fewer aggressive behaviors in film and television versions of children's stories than in the print versions of those same stcries.

This hypothesis was not supported by the data $(\mathrm{t}(17$ d.f. $)=1.38$, n.s. $)$. Mother/surrogate means for aggressive behaviors in print and visual versions were 8.82 and 7.23 respectively. The null hypothesis could not be rejected.

H7 stated:

Mother and surrogate mother characters will display fewer independent actions and emotions in film and television versions of children's stories than in the print versions of those same stories.

This hypothesis was not supported by the data. $(\mathrm{t}(17$ d.f. $)=.53$, n.s.). The null hypothesis could not be rejected. Mother/surtogate characters displayed an average of 8.11 independent actions or emotions in print versions compared to an average of 8.17 in visual versions.

Due to these findings it was decided that further t-tests would be conducted for selected individual behaviors to illuminate the changes taking place. Behaviors were selected individually by their close relationship to authority behaviors or emotions. 
TABLE 6 BEHAVIOR CATEGORIES ${ }^{3}$

\begin{tabular}{||l|c|c|c|c|c||}
\hline \multicolumn{1}{|c|}{ CATEGORY } & BOOK MEAN & STD.DEV & FLMTV MN & STD.DEV & $\mathrm{t}$ \\
\hline DOMINANT & 78.00 & 83.41 & 45.50 & 43.18 & $2.89^{\star \star}$ \\
\hline SUPPORTIVE & 78.00 & 62.83 & 52.94 & 36.56 & $2.54^{\star}$ \\
\hline DEPENDENT & 46.94 & 34.85 & 40.38 & 32.92 & 1.16 \\
\hline RANGE & 20.94 & 5.24 & 18.50 & 7.29 & 1.79 \\
\hline AGGRESSIVE & 13.50 & 22.87 & 10.55 & 17.10 & 1.38 \\
\hline INDEPENDENT & 9.05 & 7.83 & 8.16 & 8.90 & .53 \\
\hline
\end{tabular}

TABLE 7 SELECTED INDIVIDUAL BEHAVIORS ${ }^{4}$

\begin{tabular}{||l|c|c|c|c|c||}
\hline \hline \multicolumn{1}{|c|}{ BEHAVIOR } & BOOK MEAN & ST.DEV & VI MEAN & ST.DEV & $\mathrm{t}$ \\
\hline AUTHORITY & 45.12 & 67.65 & 30.18 & 34.59 & 1.38 \\
\hline NURTURES & 26.31 & 22.19 & 22.37 & 15.15 & .96 \\
\hline WORRIED & 26.31 & 22.19 & 22.37 & 15.15 & .96 \\
\hline HOUSEWORK & 17.87 & 18.47 & 12.12 & 10.81 & 2.03 \\
\hline TIMID & 17.87 & 18.47 & 12.12 & 10.81 & 2.03 \\
\hline AFFECTION & 5.06 & 4.25 & 8.25 & 7.15 & $-2.49^{\star}$ \\
\hline COURTEOUS & 4.87 & 7.78 & 5.75 & 6.76 & -.62 \\
\hline PASSIVE & 4.87 & 7.78 & 5.75 & 6.76 & -.62 \\
\hline ABILITY & 4.50 & 6.08 & 2.25 & 3.45 & $2.80^{\star *}$ \\
\hline ADVISING & 3.87 & 5.47 & 1.43 & 1.96 & 2.09 \\
\hline HAPPINESS & 3.87 & 3.75 & 5.68 & 6.83 & -1.38 \\
\hline SELF-SACRIFICE & 3.87 & 3.75 & 5.68 & 6.83 & -1.38 \\
\hline ANNOYANCE & 3.62 & 6.57 & 5.31 & 9.00 & -1.69 \\
\hline ANGER & 2.62 & 3.91 & 3.43 & 5.64 & -.90 \\
\hline
\end{tabular}

$$
{ }^{*} \mathrm{p}<.05 \quad \text { ** } \mathrm{p}<.01
$$

${ }^{3}$ d.f. 17

${ }^{4}$ d.f. 15 
These analyses proved useful. The individual behaviors of Authority, Nurtures, Affection, Housework, Happiness, Timid, Worried, Ability, Advising, and Annoyance, and Passive were tested individually (See Table 7 for complete listing) Three behavior units yielded significant results. Ability ( $(15$ d.f. $)=2.80, p<.013$ ) had a mean of 4.50 in books compared to 2.25 in film/TV. In the Advising behavior unit the mean for print versions was 387 compared to a film/TV mean of 1.43 (t ( 15 d.f.) $=2.09, p<.055)$. The Affection behavior mean actually increased in film and television versions with a mean of 8.25 as compared to a mean of only 5.06 in print $(\mathrm{t}(15$ d.f. $=-2.49, \mathrm{p}<.025)$.

In order to further understand the decreases in the Supportive and Dominant categories, all individual behaviors within those categories were compared. While the proportions of three Supportive behaviors increased, Affection, Courtesy and Nurturance, all other Supportive behavior ratios decreased. In the case of Dominant behaviors the proportion of all behaviors decreased in the visual versions of the stories.

H8 stated:

The number of female characters will decrease in film and television versions of children's stories when compared to the original versions of those same stories.

This hypothesis was supported ( $(17$ d.f.) $=3.08, \mathrm{p}<.007$ ). The actua! number of male characters increased from an original number of 133 total male characters in 18 novels to 140 male characters in 18 films and videos. The number of female characters decreased from a high of 113 in the novels to only 88 in the visual versions of the same stories. The null hypothesis was rejected. 
H9 stated:

The percentage of story time devoted to Mother and surrogate mother characters will decrease in film and television versions of children's stories when compared to the original print versions of those same stories.

This measurement was computed by transforming the data into proportions, since the coding method, reported in the methods section, rendered percentages. The data were transformed by the arcsine (ARSIN) command in the SPSS-X software. The arcsine function stabilizes proportional data. This hypothesis was also supported (t $(17$ d.f. $)=2.91, \mathrm{p}<.010)$. The null hypothesis was rejected. 


\section{CHAPTER VI}

\section{DISCUSSION}

\section{IMPLICATIONS}

The first section addresses the implications these results might have in light of our two professed goals. The second section identifies the limitations of this study and suggests areas for further research.

Two results were intriguing in light of all the other findings, the decrease in Dominant behaviors coupled with the decrease in Supportive behaviors. Our hypotheses had predicted that dominant behaviors would indeed go down but I predicted that supportive behaviors would increase. After some consideration an interpretive framework ${ }^{5}$ was created which might explain both results and hold the clue to one of the underlying questions articulated in the introduction.

In a culture that highly values Independen:e but also supports the commandment "Obey thy Mother and thy Father" it might be difficult to fashion stories with children as main characters where exciting and interesting conflicts and dilemmas present themselves if Mother is an active main part of the story.

${ }^{5}$ This interpretation was first suggested by Dr. David Rathke in conversation prior to the data collection of this study. Dr. Rathke offered this suggestion as an explanation for the lack of mother roles in children's stories. 
The absence of mother in children's stories may be an "unintended consequence" (Giddens, 1979) of the requirements of narrative structure.

In the translation of stories from print to visual medium the compression of storyline may seek to emphasize the more exciting elements of the story--- conflict and dilemmas-- which in turn necessitates fewer dominant and supportive acts by mothers in the story. In the analysis of individual behaviors in the supportive and dominant categories the most notable declines took place in Ability and Authority behaviors for the dominant category, and housework, childcare and protection in the Supportive category. These findings suggest that adventurous and suspenseful situations would be seriously hindered by the presence of a mother figure.

Another aspect to the emphasis on adventure and excitement is that housework and childcare are cer:ainly less exciting than fighting dragons and rafting the Mississippi river. Understandably, directors might eliminate as many of the mundane tasks performed by mothers as possibie.

This preference is not wholly unrelated to the assertions of Cultivation Theory that holds that television must reach the widest possible audience. "Institutional needs and objectives influence the creation and distribution of mass produced messages which create, fit into, exploit and sustain the needs, values and ideologies of mass publics" (1986 p.23). An emphasis on action and adventure would have two effects; first, a preference would be given to male characters due to the cultural constraints that still tend to socialize females into passive roles, and there would be a tendency to 
eliminate authority figures that might constrain the actions of characters. Our findings support this proposition.

Nilsen (1971) also noted the trap of trying to appeal to the widest possible audience. She reported that in a writing course for Children's literature she was told by the instructor "the wise author writes about boys, thereby insuring himself (sic) a maximum audience, since only girls will read a book about a girl, but both boys and girls will read about a boy." (p.918).

These two frameworks are not unconnected. The first framework suggests that the mother is too powerful a figure in a child's life to allow free-wheeling action and adventure. The second suggests that an emphasis on action and adventure in order to appeal to the largest audience also would exclude mothers because the media's idea of mother is domestic. These frameworks are highly related; each would reinforce and support the positions of the other.

These two frameworks and their relationship would explain several of the findings of this study. First it would explain the decrease in both supportive and dominant behaviors. Secondly, it would explain the absence of mothers from a large percentage of children's stories. Third, it would explain the decrease in story iime for mothers and surrogates in the visual versions. Finally, it also would explain the increase in affectionate behaviors by mothers and surrogates, in that the only behaviors relegated to mothers which are visually appealing to large audiences are a mother hugging, caressing or cuddling a child. 
Other findings that were consistent with prior content analyses do much to make clear that women are continually under-represented in visual media. The result that fewer female characters were found in the visual versions than in the print versions bolsters the original premise of the Vest study, which suggested that fewer female characters on television were a result of the modes of production. While he was unable to find this phenomenon in his sample of pilot scripts, this study did find there was indead a significant reduction in female characters when the stories were translated from the original novel to a visual medium.

One major influence on the production structure that may account for this phenomenon is the status of a "Male star". According to Richard Corliss, fernale stars are "deemed too small, too soft to show muscle at the box office" (Time, 1991). This lack of box office power perceived by the motion picture industry may be one contributing factor to the reduction of female roles in films and television. "According to the Screen Actors Guild only $29.1 \%$ of all feature film roles in 1989 went to women" (Time, 1991 p.58). Actress Meryl Streep predicted in that by the year 2000 the figure would be reduced to $13 \%$ (p.58).

Three findings in regard to women and the mass media appear to be working simultaneously to influence female depictions. First, women have fewer roles, second, women are often portrayed as mothers and wives in these same media, and third, wives and mothers are often limited to stereotypical behaviors in filmis and television. 
If one purpose of media research is to highlight areas that are problematic for segments of the population then it seems pertinent to point out that the role of mother is not static but evolving. 
Limitations

Two major limitations must be considered in this study, the first is associated with interpretation, the second with limited resources.

It is obvious when one looks at textual material and codes for behaviors explicitly stated in books that an accurate and reliable measurement is possible. However, this assumption cannot be made with visual material. Unfortunately, no matter how firm our intentions to record only observable and discrete behaviors, a great deal of what is recorded is largely inferred from contextual variables. In addition, due to unforeseen pressures, the behavior coding was conducted almost exclusively by me, with some help from my husband and a close friend, what biases this has introduced into the study one cannot know.

Second, because of this study's focus on the mother role in cinililien's books and because it was further limited to novels which had been translated to a visual medium, and further only those which were available to the researcher, a very small sample size was gathered.

The snall sample size has two effects. First, it reduced the power and decreased confidence in the null results for all hypotheses that were not confirmed. Second, limitations in the availability of research materials might have resuited in unintended biases in the material sample and influenced our findings. 
Suggested Research

I keep returning to one theme throughout this paper and it is the lack of mothers in children's stories. Future research might illuminate the relationship between the lack of mothers in children's stories and conflict in dramatic narrative. 


\section{References}

Act (1990). TV can promote children's reading. Children Today 19(3) p.2.

Allen, R. C. (Ed.) (1987). Channels of Discourse, Chapel Hill: University of North Carolina Press.

Anderson, J.P. (1981) Research on chidren and television: A critique. Journal of Broadcasting, 25(4) 395-400

Babbie, E. (1992). The Practice of Social Research, 6th Ed. Belmont CA: Wadsworth.

Babbitt, L. and Jablin, F. (1985). Characteristics of applicants' questions and employmeril screening interview outcomes. Human Communication Research, $11(4), 507-535$.

Bandura, A. (1977) Social Learning Theory, Englewood Cliffs, NJ: Prentice Hall

Bandura, A. (1978) Social learning theory of aggression, Journal of Communication, 28(3) 12-27.

Berger, P. \& Luckmann, T. (1966) The Social Construction of Reality. Garden City, NJ: Doubleday \& Company.

Beuf, A, (1974) Doctor, lawyer, household drudge. Joumal of Communication, 24(2) 142-145. 
Bridges, J.S. \& Orza, A. M. (1992) The effects of employment role and motive for employment on the perceptions of mothers. Sex Roles 27(71/8) 331-343.

Buerkel-Rothfuss, N.L.,Greenberg, B., Atkin, C., Neuendorf, K. (1982) Learning about the family from television. Joumal of Communication, 32(3) 191-201.

Cantor, M. (1990) Prime-time fathers: A study in continuity and change. Critical Studies in Mass Communication. $7275-285$.

Chodorow, N.(1978) The Reproduction of Mothering: Psychoanalysis and the sociology of gender. Berkeley: University of California Press.

Collins, L.J., Ingoldsby, B. \& Dellmann, M. (1984). Sex-role stereotyping in children's literature: A change from the past. Childhood Education, 60, 278-285.

Corliss, R. (1991). Women on the verge of a nervy breakthrough. Time, 137 (7), 58-60.

Craig, R.S., (1992) The effect of television day part on gender portrayals in television commercials: A content analysis. Sex Roles, 26 (56) 197-211.

Davis, D.M. (1990) Portrayals of women in prime-time network television: Some demographic characteristics. Sex Roles, 23 325-332.

Dorr, A. \& Kunkel, D. (1990) Children and the media environment rage and constancy amid change. Communication Research, 17(1) $5-25$. 
Fellman, A. C. (1990). Laura Ingalls Wilder and Rose Wilder Lane:

The politics of a mother-daughter relationship. Signs, 15 (3), 535-561.

Gerbner, G., \& Gross, L. (1976) Living with television: The violence profile. Joumal of Communication, 26 173-199.

Gerbner, G., Gross, L., Morgan, M. \& Signorielli, N. (1986) Living with television: The dynamics of the cultivation process. in Perspectives on Media Effects ed. Bryant, J. 18-35.

Giddens, A. (1979). Central Problems in Social Theory, Berkeley, CA: University of Calif. Press.

Haight, G. (1989) The perilous journey from book to screen: A thors who sell their books to TV have to learn to live with a whole new set of rules. Puolisher's Weekly, 235(8) 137.

Hawkins, J. W. \& Aber, C. S. (1993). Women in Advertisements in Medical Journals. Sex Roles, 28 (3/4), 233-242.

Heintz, K.E. (1992) Children's favorite TV families: a descriptive analysis of role interaction. Journal of Broadcasting and Electronic Media. 36(4) 443-451.

Hillman, J.S. (1974) An analysis of male and female roles in 2 periods of children's literature. Journal of Educational Research, 68 84-88.

Honey, L. (1984) Creating Rosie the Riveter:Class, gender and propaganda during World War II. Amherst: University of Massachusetts Press. 
Jaeger, R.M. (1990). Statistics A Spectator Sport, Newbury Park, CA: Sage.

James, N.C. \& Mc Cain, T.A. (1982) TV games preschool children play: patterns, themes, and uses. Journal of Broadcasting, 26(4) 783-800.

Kortenhaus, C.M. and Demarest, J. (1993). Gender role stereotyping in children's literature: An update. Sex Roles $28(3 / 4), 219-232$.

Kumit, P. (1992) TV is the only universai experience American kids have in common. Broadcasting, 122 (38) p.19.

Lovdai, L. (1989). Sex role messages in television commercials: An update. Sex Roles, 21 (11/12) 715-724.

Meadowcroft, J. \& Reeves, B. (1989). Influence of story schema development on children's attention to television. Communication Research, 16(3) 352-374.

Moore, M. L., (1992). The family as portrayed on primetime television, 1947-1990: Structure and characteristics. Sex Roles, 26 (1/2), 41-61.

Nilsen, A. P. (1971). Women in children's literature. College English, 32, 918-926.

Norusis, M.J. \& SPSS,INC. (1988). SPSS-X Introductory statistics guide: SPSS-X release 3. Chicago: SPSS,INC.

Perse, E.M.; Pavitt, C. \& Burggraf, C.S. (1990). Implicit theories of marriage and evaluations of marriage on television. Human Communication Research, 16 (3) 387-408. 
Pope, D. \& Quinn, N. (1990) Untitled. Signs, 3 441-445.

Press, A. (1991). Women watching television: Gender, class, and generation in the American television experience. Philadelphia: University of Pennsylvania Press.

Reeves, B. \& Miller, M.M. (1978) A multidimensional measure of children's identification with television characters. Journal of Broadcasting, 22 71-86.

Rosengren, K. \& Windahi, S. (1989). Media Matter TV use in Childhood and Adolescence. Norwood, N.J.: Ablex.

Schrag, R.L. (1991) Narrative rationality and first stories: Pedagogical implications for children's television. Communication Education, 40(4) 313-320.

Seidman, S. A. (1992.) An investigation of sex role stereotyping music videos. Journal of Broadcasting and Electronic Media, 3209.216.

Signorielli, N. \& Lears, M. (1992) Children's television and conceptions about chores: Attitudes and behaviors. Sex Roles $27(3 / 4)$ 157-170.

Signorielli, N. (1982) Marital status in television: A case of reduced options. Journal of Broadcasting, 26(2) 585-597.

Spigel, L. (1989). The domestic economy of television viewing in postwar America. Critical Studies in Mass Communication, 6 (4) 337-354.

Tobin, L. (1900) The social construction of the tender mother. Signs, 28 (3) 000-000. 
Vande Berg, L.R. \& Streckfuss, D. (1992) Prime time television's portrayal of women and world of work: A demographic profile. Journal of Broadcasting and Electronic Media, 3 195-207.

Vest, D. (1992) Prime time pilots: A content analysis of changes in gender representation. Journal of Broadcasting and Electronic Media, 3 25-35.

Weiss, A. J. \& Wilson, B.J. (1993) Emotional Portrayals and humor in Farnily television series that are popular among children. Paper presented at ICA conference May 1993, Washington, D.C.

Welch, R.L.; Huston-Stein, A.; Wright, J. \& Plehal, R. (1979). Subtle sex-role cues in children's commercials. Journal of Communication, 202-209.

Wicks, R. \& Drew, D. (1991). Learning from news: Message consistency and medium on recall and inference making. Joumalism Quarterly, 68 (1) 155-164.

Williams, J. A.;Vernon,J.;Williams,M.; and Malecha, K. (1987).

Sex role socialization in picture books:An update. Social Science Quarterly, 68, 148-156.

Williams, J.E. and Bennett, S. (1975). The definitions of sex stereotypes via the adjective checklist. Sex Roles, 1(4) 327-337. 


\section{Appendix A}

Definitions utilized by coders for 41 individual behavior classifications.

Ability was defined for the coders as physical mental power to perform, skill or talent (Webster's II, 1988 p.66). Displayed as: Accomplishing or performing a task outside everyday duties, power or skill outside the domestic sphere.

Adventurous was defined as inclined to undertake new and daring enterprises, reckless: mischievous (ibid. p. 81) Displayed as: extreme cases of curiosity, going into potentially dangerous situations when others will not, encouraging others in new and different undertakings.

Advising was defined as offering advice, recommending or suggesting, informing (ibid. p.81). Displayed as: Recommending or suggesting alternate course cf action, sought for counsel, consulted.

Affection was defined as a fond or tender display of feelings toward another (ibid. p.83). Displayed as: This behavior was reserved for physical displays of affection in order to separate it clearly from nurures. All kisses goodright, stroking of hair, caresses, rocking while holding child on lap, etc.

Anger: extreme displeasure, hostility, or indignation (ibid. p.107) Displayed as: Shouting or verbally expressing anger, administering harsh punishment, (not physical punishment this is categorized as violence) also nonverbal symbols, tight lips, narrowed eyes, folded arms etc.

Annoyance was defined as bothered or irritated by some one or something (ibid. p.110). Displayed as: frowns, grimaces, hands on hips, sharp sighs or exhalations.

Authority was defined as the power to command, exact obedience, determine or jua'ge (ibid. p.139). Displayed as: Verbal commands, directives, obeyed, appealed to as judge or authority (as in conflict resolution).

Childcare Tasks were defined as tasks related to the care of children. Displayed as: Bathing, putting to bed, dressing, feeding, brushing/combing hair, washing face or harids of child, putting away toys, washing diapers, etc.

Courage was defined as facing danger with self -possession, conficlence, resolution, bravery and valor (ibid. p. 320). Displayed as: Facing a dangerous situation when no one else will, going into dangerous situations on behalf of another, facing violence victimization without submission. 
Courteous was defined as graciousness, good manners, polite. (Ibid. p. 320) Displayed as: Acting as hostess, verbal, (thank you, please, pardon me) issuing invitations, table manners, observing the proprieties.

Criticism was defined as judging harshly or adversely (Ibid. p.328). Displayed as: verbal reprimands, sarcasm, also nonverbal actions, facial expressions, disgust.

Curiosity was defined as a desire to learn or know, aroused interest (lbid. p.337). Displayed as: Action to find out something, venturing into unknown territories to find out something, or nothing.

Dependency was defined as subordinate, reliance on another for support or aid (Ibid. p. 363). Displayed as: Helped physically out of wagons, carriages, through doors or difficult physical spaces. Told what to do, directed in behaviors or actions by someone who must be obeyed.

Exhaustion was defined as worn out or tired, without further resources (Ibid. p.452). Displayed as: Physical manifestations of fatigue, drooping shoulders, sitting heavily into chairs, falling asleep quickly or inappropriately.

Fearful was defined as alarmed, agitated or apprehensive due to the expectation or realization of danger (Ibid. p. 468) Displayed as: Screaming, cowering, running, hiding, facial expressions of fear.

Foolish was defined as lacking good sense or judgement (Ibid. p. 494). Displayed as: Commits acts judged to be foolish ty audience and/or other characters. Acts in ways which harm others without thought to consequences of actions.

Happiness/Playful was defined as enjoying or displaying pleasure or joy, carefree, (Ibid. p. 564) Displayed as: Smiling, laughing, running with children, lighthearted actions, great relief, great joy.

Housework/cooking was defined as the various duties involved in housekeeping,(Ibid. p. 595) Displayed as: cleaning, cooking, dusting, mopping, sweeping, washing, etc.

Ignorance was defined as lack of knowledge or education (Ibid. p. 608). Displayed as: Saying or doing the wrong thing, (obvious to viewer or other characters), poor grammar, poor general knowledge. 
Ill or injured was defined as not healthy, suffering in physical distress, wounded. (Ibid. pp.609 \& 619). Displayed as: facial expressions of illness or pain, crying out in pain or suffering, helped by another because of pain.

Intelligence was defined as applying, acquiring knowledge, superior mental abilities (Ibid. p. 635). Displayed as: Has knowledge of plan not possessed by others, deferred to in opinion or mental actions, Referred to by other characters as intelligent, knowledgeable, refers to self as intelligent or knowledgeable.

Makes Things go Smoothly was defined as helping things function well within the home, averts conflicts or problems through quick actions. Displayed as: Removing objects of contention, temoving or concealing individuals from one another, overcomes resistance.

Managing was defined as arranging and supervising. (Ibid. p. 721) Displayed as: This was separated from authority by using it as a category for outside the family sphere only, used as directing or supervising hired help, repairmen, maids, storekeepers etc.

Manipulated was defined as controlled or influenced shrewdly or deviously by another person (Ibid. p. 723). Displayed as: lied to, or led on, made to feel inadequate or guilty.

Neglect was defined as ignore, disregard, or failing to give proper attention or consideration to, (Ibid. p. 788) Displayed as: children or other person for whom mother responsible in obvious need or state of neglect, dirty, frightened, in danger etc. and mother oblivious or uncaring.

Nurtures was defined as nourishes, rears, influences, trains and educates, helps grow and deve!op. (Ibid. p. 808) Displayed as: Singing to, talking with, listening to, helping, reading to, supporting, guiding.

Passive was defined as not responding, accepting without resistance or objection, not participating, waiting for or watching others (Ibid. p. 859). Displayed as: Not objecting when facial expressions say character would like to, being told to wait while someone else faces danger, watching while someone else acts, dances sings, plays, etc.

Problem Solving was defined as finding solutions to problems or dilemmas, acting to resolve a problem. Displayed as: Coming up with the right suggestion, displaying ability by resolving dangerous or tricky situations. 
Protects was defined as to keep from harm or injury (ibid. p. 946) Displayed as: Physically removing someone/thing from danger, or verbally protecting from harsh words or criticism.

Reassures was defined as to restore confidence, affirm, (Ibid. p. 980) Displayed as: telling someone again that they are doing right, to support prior decisions.

Rescued was defined as saved from danger, (Ibid. p. 999) Displayed as: physically saved from danger by the appearance of someone else.

Resolves conflicts was defined as reaching a solution or to arrive at decisions about conflicts, (Ibid. p. 1001). Displayed as: Stepping into conflicts with others and defusing tempers, deciding rightness or wrongness, etc.

Sadness was defined as unhappiness or sorrow, (Ibid. p. 1030) Displayed as: facial expressions, tears, crying out in anguish.

Self-deprecating was defined as belittling or detracting from one's self, (Ibid. p. 1058). Displayed as: Verbal expressions of that's too much for me, too fancy etc. or I'm not worth things so extravagant etc.

Self Sacrificing was defined as sacrifice of one's own interests or wants for sake of others, (Ibid. p. 1060). Displayed as: giving up wants or needs for others with obvious facial expressions of regrets, declining food, gifts, pleasures etc. with obvious regret.

Special Powers were defined as powers which were particular to the character and not readily available to others in the story. Displayed as: magical ability, psychic ability, intuition or heightened sense of awareness, and extraordinary physical strength due to extreme danger.

Surprise was defined as to encounter suddenly, shocked, taken unawares, (Ibid. p. 1166) Displayed as: facial expressions of surprise, shock, or verbal expressions of surprise or shock.

Timid was defined as shrinking from difficult or dangerous situations, shy, (tbid. p. 1211). Displayed as: stepping back from or retiring physically or verbally from another, or from a situation.

Victimized was defined as subjected to harm or injury, harmed or killed by another, (Ibid. p. 1286). Displayed as: Injury at hands of another, not only physical injury violence, but fraud or deceit, harmed in some way purposefully by someone else. 
Violence was defined as physical force employed to damage or abuse, or punish, (Ibid. p. 1289). Displayed as: hitting slapping pulling hair any physical action which causes pain, spanking, pulling ears, etc.

Worried was defined as uneasy or troubled, distressed, (Ibid. p. 1329). Displayed as: highly concerned, facial expressions of anxiety, physical displays of worry, nail biting, hair pulling, wringing hands etc. 
Appendix B Behavior Codesheet

Title: Character:

Place mark next to the appropriate terms each time the behavior occurs.

Dominant terms: Ability

Adventurous
Advising
Authority
Courage
Intelligence
Managing
Problem solving
Special Powers

Dependent Terms: Dependency

Exhaustion
Fearful
Foolish
Ignorant
Ill or Injured
Manipulated
Passive
Rescued
Self-deprecating
Timid
Victimized
Worried

Supportive Terms: Affectionate

Childcare tasks

Courteous

Housework, cooking

Makes things go smoothly

Nurtures

Protects

Reassures

Self-Sacrificing

Resolves conflicts

Aggressive Terms: Anger

Annoyance

Manipulation

Criticism

Neglect

Violence (physical or verbal)

Independent Action/Emotion Terms: Happiness/Playful

Sadness

Surprise

Curiosity 